\title{
Glucose Transporters in Diabetic Kidney Disease-Friends or Foes?
}

\author{
Anita A. Wasik and Sanna Lehtonen* \\ Department of Pathology, University of Helsinki, Helsinki, Finland
}

Diabetic kidney disease (DKD) is a major microvascular complication of diabetes and a common cause of end-stage renal disease worldwide. DKD manifests as an increased urinary protein excretion (albuminuria). Multiple studies have shown that insulin resistance correlates with the development of albuminuria in non-diabetic and diabetic patients. There is also accumulating evidence that glomerular epithelial cells or podocytes are insulin sensitive and that insulin signaling in podocytes is essential for maintaining normal kidney function. At the cellular level, the mechanisms leading to the development of insulin resistance include mutations in the insulin receptor gene, impairments in the phosphoinositide 3-kinase (PI3K)/AKT signaling pathway, or perturbations in the trafficking of glucose transporters (GLUTs), which mediate the uptake of glucose into cells. Podocytes express several GLUTs, including GLUT1, GLUT2, GLUT3, GLUT4, and GLUT8. Of these, the most studied ones are GLUT1 and GLUT4, both shown to

OPEN ACCESS

Edited by:

Toru Hosoi,

Hiroshima University, Japan

Reviewed by:

Thierry Coppola,

Centre National de la Recherche Scientifique (CNRS), France Jean Mazella,

UMR7275 Institut de

Pharmacologie Moléculaire et Cellulaire (IPMC), France

*Correspondence: Sanna Lehtonen sanna.h.lehtonen@helsinki.fi

Specialty section: This article was submitted to Cellular Endocrinology, a section of the journal Frontiers in Endocrinology

Received: 23 January 2018 Accepted: 22 March 2018

Published: 09 April 2018

Citation:

Wasik AA and Lehtonen S (2018) Glucose Transporters in Diabetic Kidney Disease - Friends or Foes?

Front. Endocrinol. 9:155. doi: 10.3389/fendo.2018.00155 be insulin responsive in podocytes. In the basal state, GLUT4 is preferentially located in perinuclear and cytosolic vesicular structures and to a lesser extent at the plasma membrane. After insulin stimulation, GLUT4 is sorted into GLUT4-containing vesicles (GCVs) that translocate to the plasma membrane. GCV trafficking consists of several steps, including approaching of the GCVs to the plasma membrane, tethering, and docking, after which the lipid bilayers of the GCVs and the plasma membrane fuse, delivering GLUT4 to the cell surface for glucose uptake into the cell. Studies have revealed novel molecular regulators of the GLUT trafficking in podocytes and unraveled unexpected roles for GLUT1 and GLUT4 in the development of DKD, summarized in this review. These findings pave the way for better understanding of the mechanistic pathways associated with the development and progression of DKD and aid in the development of new treatments for this devastating disease.

Keywords: diabetic kidney disease, glucose transporters, insulin resistance, insulin signaling, podocyte, type 2 diabetes

\section{INTRODUCTION}

Diabetic kidney disease (DKD) is the serious complication of diabetes. Clinically, DKD manifests as progressive albuminuria and gradual decline in estimated glomerular filtration rate. The cumulative incidence of DKD in patients with type 1 diabetes (T1DM) is $20-40 \%$ after $20-25$ years of diabetes (1). Type 2 diabetes (T2DM) may remain undiagnosed for several years after onset of the disease, and thus patients may have DKD already at the time of diagnosis. The prevalence of low-level albuminuria in patients with T2DM has been reported to be $24.9 \% 10$ years after diagnosis (2). DKD due to either T1DM or T2DM is the leading cause of end-stage renal disease.

The pathophysiological mechanisms leading to the development of DKD remain incompletely understood. Genetic factors, inflammation, and metabolic disturbances are known to be involved 
[reviewed in Ref. (1)]. Hyperglycemia plays a central role, and also insulin resistance is a risk factor for DKD and contributes to the development of the disease (3). This is supported by studies showing that insulin resistance correlates with microalbuminuria in diabetic (4-7) and non-diabetic subjects (8). Albuminuria develops when the glomerular filtration barrier (GFB), consisting of the fenestrated endothelial cells, the glomerular basement membrane (GBM), and the glomerular epithelial cells or podocytes (Figures 1A,B), is disturbed. Podocytes are polarized, highly specialized, and terminally differentiated cells. The foot processes of neighboring podocytes interact with specialized cell to cell junctions called slit diaphragms (SD) located between the basal and apical domains of the foot processes (Figures 1A,B). Podocyte injury has been suggested to have a pivotal role in the pathogenesis of DKD (9). During podocyte injury, podocytes efface (flatten) and detach from the GBM, and the frequency of SDs is reduced.

Interestingly, podocytes are insulin sensitive (10) and have been shown to develop insulin resistance in animal models of diabetes (11). Concomitantly, insulin resistance has been proposed as one of the key mechanisms that associates with the development and progression of DKD (12). This raises interest in the pathways that regulate insulin sensitivity of podocytes and specifically in the perturbations in these pathways leading to the development of insulin resistance of these specialized cells. Understanding the mechanisms that lead to reduced response of podocytes to insulin and the functional consequences will help to design treatment strategies to prevent the progression of DKD. Several recent, excellent reviews summarize the effects of insulin on podocytes and regulation of renal insulin signaling $(13,14)$. In this review, we summarize insulin signaling in podocytes in the context of glucose uptake and specifically concentrate in describing the current knowledge on the glucose transporters (GLUTs) and the regulation of GLUT trafficking in podocytes.

\section{INSULIN SIGNALING PATHWAYS THAT REGULATE GLUT TRAFFICKING}

\section{Insulin Signaling via the PI3K/AKT Pathway}

The actions of insulin in cells are initiated by binding of insulin to its receptor on the cell surface (Figure 1C). Insulin receptor (IR) is a heterotetrameric complex, consisting of two extracellular $\alpha$ subunits that bind insulin and two transmembrane $\beta$ subunits

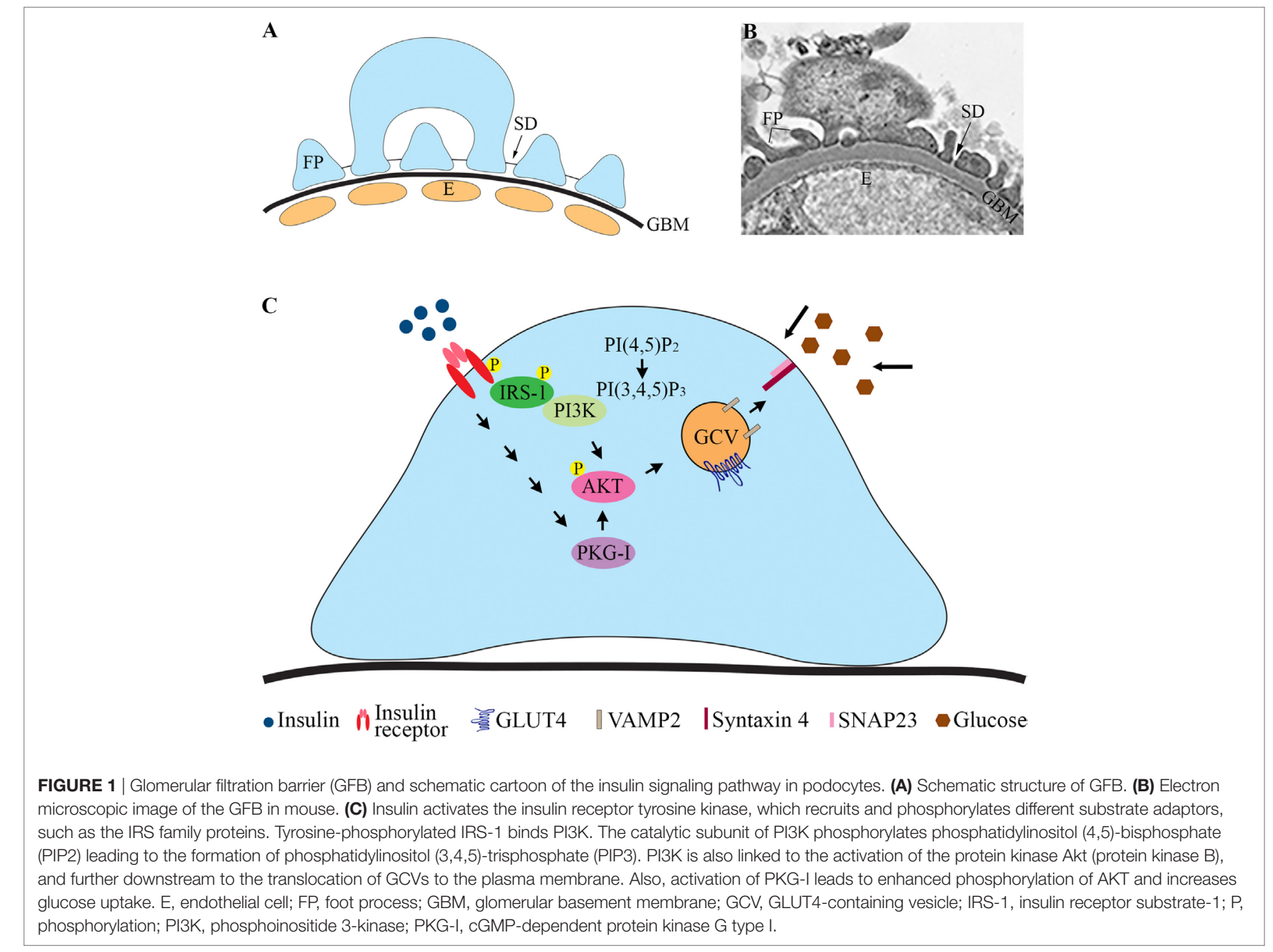


with tyrosine kinase activity (15). IR exists in two forms, A and B. IR-A is ubiquitously expressed, and IR-B is expressed in insulinsensitive tissues such as liver, muscle, adipose tissue, and kidney. Insulin may also bind to and signal via insulin-like growth factor I (IGF-IR) or IR/IGF-IR hybrid receptors, although insulin binds to IGF-IR at much lower affinity than to IR [reviewed in Ref. (16)].

Binding of insulin to the $\alpha$ subunit of IR induces transphosphorylation of one $\beta$ subunit by another on specific tyrosine residues, resulting in increased catalytic activity of the kinase. The receptor further undergoes autophosphorylation at other tyrosine residues. The activated receptor then phosphorylates tyrosine residues on intracellular substrates, including members of the insulin receptor substrate family (IRS1-4) (17). Upon tyrosine phosphorylation, IRS proteins interact with the $\mathrm{p} 85$ regulatory subunit of the PI3K, which leads to its activation and translocation to the plasma membrane. PI3K catalyzes phosphorylation of phosphatidylinositol 4,5-bisphosphate to form phosphatidylinositol 3,4,5-trisphosphate $\left(\mathrm{PIP}_{3}\right)$. Insulin-stimulated increase in $\mathrm{PIP}_{3}$ results in the phosphorylation and activation of the serine/threonine kinase $\mathrm{AKT}$, also called protein kinase $\mathrm{B}(\mathrm{PKB})$, leading to a cascade of signaling events that coordinate trafficking of GLUT4 to the plasma membrane (Figure 1C). In the absence of insulin signal, GLUT4 resides in cytoplasmic vesicular structures. Upon insulin stimulation, GLUT4 is sorted into insulin-responsive vesicles (IRVs) that translocate to the plasma membrane leading to glucose uptake into cells [for reviews on adipocytes and myocytes, see Ref. $(18,19)]$. These vesicles are often called GLUT4 storage vesicles or IRVs. However, the various vesicles containing GLUT4 are hard to distinguish from each other (18) and therefore we will call them here generally as GLUT4-containing vesicles (GCVs). Various studies indicate that not only PI3K is essential for GLUT4 translocation and glucose uptake (20) but also other signals, generated by insulin, participate in stimulating translocation of GLUT4 (21-24). IR has also been shown to localize in lipid rafts on the plasma membrane and to induce glucose uptake into cells via a PI3K-independent pathway involving $\mathrm{Cbl} / \mathrm{Cbl}$-associated protein (25)/TC10 (22). This pathway is involved in insulin signaling and glucose uptake in adipose tissue and muscle cells (22), but apparently the pathway is not active in podocytes (26).

Podocytes express all the elements of the insulin signaling cascade, such as IR, IRS1 (10), and IRS2 (27). Analyses have demonstrated that podocytes have the highest levels of both IR and IRS1 expression when compared with endothelial and mesangial cells in primary culture (28). Similar to adipocytes and muscle cells, podocytes respond to insulin by activating the PI3K and mitogen-activated protein kinase signaling pathways, but only $\mathrm{PI} 3 \mathrm{~K}$ is implicated in glucose uptake. In podocytes, insulin induces rapid translocation of GLUT4 to the plasma membrane similarly as in muscle cells and adipocytes (10). This induces remodeling of the cortical actin cytoskeleton and contraction (26), allowing podocytes to physiologically respond to the increased glomerular pressure and filtration that happen after a meal.

\section{Regulation of the PI3K/AKT Pathway in Podocytes}

Defects in any site of the insulin signaling pathway, both upstream and downstream of IRS, may arise and disrupt the signaling cascade. Examination of the protein and activity levels of the IR, $\mathrm{PI} 3 \mathrm{~K}$, and AKT demonstrate a clear disturbance in these signaling molecules in diabetic conditions (29). Downregulation of IR-B subunit was observed in diabetic podocytes (11). Furthermore, specific deletion of IR in podocytes in mice induces a disease state reminiscent of DKD, without hyperglycemia (3). This demonstrates the necessity of insulin signaling in podocytes for maintaining normal kidney function.

Multiple studies suggest that inhibition of AKT activation is one of the key factors leading to insulin resistance of podocytes. In podocytes of $\mathrm{db} / \mathrm{db}$ mice, a model for T2DM, insulinstimulated AKT phosphorylation (activation) is lost (11). A similar loss of insulin signaling via PI3K was found in the glomeruli of streptozotocin (STZ) and Zucker rats (28), models for T1DM and T2DM, respectively. The interpodocyte SD with its major component nephrin (30) has emerged as an important signaling center, as nephrin associates with a number of membrane and cytosolic proteins thereby connecting the SD to various signaling pathways (31-33). Concomitantly, nephrin has been shown to activate AKT via PI3K $(33,34)$. Interestingly, nephrin has been found to be downregulated or mislocalized in various models of DKD (35-40).

The negative regulators of the PI3K signaling pathway include lipid phosphatases SHIP2 (SH2-domain-containing inositol polyphosphate-5 phosphatase 2) and phosphatase and tensin homolog (PTEN) (41). These phosphatases dephosphorylate $\mathrm{PI}(3,4,5) \mathrm{P}_{3}$ to $\mathrm{PI}(3,4) \mathrm{P}_{2}$ and $\mathrm{PI}(4,5) \mathrm{P}_{2}$, respectively (42). In line with this, overexpression of SHIP2 downregulates insulin response in cultured human podocytes by reducing AKT activation (43). Furthermore, SHIP2 expression was found to be elevated in glomeruli of insulin resistant obese Zucker rats prior to the rats developed albuminuria (43). Insulin resistance in podocytes due to high glucose could also be a consequence of increased PTEN protein levels, which occurs in an AMP-activated protein kinase (AMPK)-dependent manner (44). Interestingly, lack of Irs2 renders podocytes insulin resistant due to upregulation of PTEN (27). High glucose also increases the expression of protein tyrosine phosphatase SHP-1, conferring to insulin unresponsiveness of podocytes (45). Studies have also shown that in glomeruli of $\mathrm{db} / \mathrm{db}$ mice, upregulation of $\mathrm{C}$-jun $\mathrm{N}$-terminal kinase, a negative regulator of insulin signaling, may result in the inability of podocytes to respond to insulin (46).

\section{Insulin Signals via the PKG Pathway in Podocytes}

Another signaling pathway that is activated by insulin and stimulates glucose uptake into podocytes is the cGMP-dependent protein kinase $\mathrm{G}$ (PKG) pathway (44), which is also involved in glucose uptake into smooth muscle cells (47). cGMP-dependent protein kinase $\mathrm{G}$ type I (PKG-I) exists as two isoforms, I $\alpha$ and I $\beta$. Dimerization of two PKG-I subunits increases the catalytic activity of PKG-I and consequently enhances its biological action (48). The PKG-I $\alpha$ isoform is expressed in cultured rat podocytes, in which the activation of PKG-I by insulin or hydrogen peroxide leads to the activation of the insulin signaling pathway via increased phosphorylation of IR and AKT. This enhances translocation of GLUT4 to the plasma membrane and increases glucose 
uptake into cells (Figure 1C) (49). The effect is abolished by a PKG-I inhibitor confirming the role of PKG-I in glucose uptake into podocytes (49).

\section{Regulation of the PKG Pathway in Podocytes}

In podocytes, $\mathrm{PKG}$-I $\alpha$ is mainly expressed in its monomeric form (50). Insulin increases activation (dimerization) of PKG-I $\alpha$ in a ROS-dependent manner $(50,51)$. Insulin may also activate PKGI $\alpha$ via TRPC6, increasing the permeability of podocyte monolayers to albumin (50). PKG-I $\alpha$ is upregulated in the glomeruli isolated from obese, hyperinsulinemic, and insulin-resistant Zucker rats compared to lean controls (52).

\section{REGULATION OF GLUT TRAFFICKING IN PODOCYTES}

\section{GLUTs and Their Translocation Machinery}

Thus far 14 members belonging to the family of facilitative GLUTs have been identified in mammals (53). The facilitative GLUTs, which mediate uptake of glucose into cells down its concentration gradient, are either constitutive or inducible by insulin. Constitutive GLUTs, such as GLUT1, transport glucose into cells at basal condition, and GLUT4 is the major insulin-inducible GLUT. In adipocytes and myocytes in the basal state, GLUT4 is preferentially located in the intracellular vesicular compartments and slowly cycles to the plasma membrane and back. However, upon insulin stimulation, GLUT4 is translocated fast to the plasma membrane in insulin-responsive GCVs [reviewed in Ref. $(18,19)]$.

GLUT4-containing vesicle trafficking has been studied extensively in adipocytes and myocytes [reviewed in Ref. $(18,19,54)]$. GCV translocation occurs in multiple stages including approaching, tethering, docking, and fusion. The cytoskeleton provides a route for the GCVs to approach the plasma membrane. Depending on the cell type and distance to be trafficked, both actin-myosin and microtubule-kinesin machineries are utilized for GCV translocation (55). An increasing amount of evidence supports a critical role for actin in GLUT4 translocation $(10,55-57)$. Insulin elicits a rapid, dynamic remodeling of actin filaments into a cortical mesh in various insulin-sensitive cell types, such as differentiated muscle cells, adipocytes, and podocytes $(26,57,58)$. Cortical actin is a necessity for GLUT4 translocation and pharmaceutical disruption of cortical actin filament formation inhibits insulin-stimulated GLUT4 translocation (56). The second step includes two processes: tethering and docking. Actin and the exocyst complex proteins help to tether the GCVs to the plasma membrane (18), and docking is mediated by the assembly of the $\mathrm{N}$-ethylmaleimide-sensitive factor attachment protein receptor (SNARE) complex $(59,60)$; reviewed in Ref. (61). The SNARE complex includes a vesicle-SNARE (v-SNARE) on GCVs, vesicle-associated membrane protein 2 (VAMP2), and target-SNAREs (t-SNARE) on the plasma membrane, such as syntaxin 4 and synaptosome-associated protein, $23 \mathrm{kDa}$ (SNAP23) $(62,63)$. The last step of GCV trafficking to the cell surface is fusion, in which a specific interaction between $\mathrm{v}$-SNARE and
t-SNARE proteins allows merging of the lipid bilayers of the GCVs and the plasma membrane [reviewed in Ref. $(18,61)]$.

\section{GLUTs Expressed in Podocytes}

Podocytes express several GLUTs, including GLUT1 (10, 64), GLUT2 (65), GLUT3 (64), GLUT4 (10, 64-66), and GLUT8 (66).

\section{GLUT1}

GLUT1 regulates glucose uptake at the basal stage in podocytes, but interestingly, it has also been shown to respond to insulin stimulation in these cells (10). GLUT1 has a vesicular distribution within the cytoplasm and at the plasma membrane, appearing both at apical and basolateral domains of the podocyte foot processes in human glomeruli ex vivo (10). The expression of GLUT1 mRNA in the glomeruli of normoalbuminuric T1DM patients was shown to be downregulated, but glomeruli from T1DM patients with microalbuminuria presented increased GLUT1 mRNA expression compared with non-diabetic controls (67). The expression of GLUT1 mRNA and protein followed a similar pattern in the glomeruli of $\mathrm{db} / \mathrm{db}$ mice (67). Upregulation of GLUT1 was also described in the glomeruli of the STZ-induced rats (68). Studies in cultured cells revealed that GLUT1 expression is elevated in cultured human podocytes exposed to high glucose (69). A similar increase was observed in cultured mesangial cells exposed to high glucose and this associated with increased glucose uptake (70) and stimulated production of extracellular matrix proteins (64). Studies in mice overexpressing GLUT1 in either mesangial cells or podocytes revealed interesting cell typespecific outcomes in terms of DKD. Overexpression of GLUT1 in mesangial cells in mice mimicked typical features of diabetic glomerular disease, without diabetes or hypertension (71). However, podocyte-specific overexpression of GLUT1 in diabetic mice reduced mesangial expansion and fibronectin accumulation, both typical features of DKD (72). This could be mediated by reduced glomerular expression of vascular endothelial growth factor, known to contribute to mesangial matrix accumulation (72). It thus appears that increased expression of GLUT1 in mesangial cells is deleterious whereas increased expression of GLUT1 in podocytes protects against DKD. A protective role for GLUT1 is supported by the finding that peroxisome proliferator-activated receptor (PPAR) $\gamma$ agonist rosiglitazone, shown to prevent kidney disease in a mouse model of T1DM (73) and to reduce albuminuria in patients with T2DM (74), increases glucose uptake into podocytes by enhancing membrane localization of GLUT1 (75).

\section{GLUT4}

GLUT4 has a cytoplasmic, vesicular distribution in the resting cell, but upon insulin stimulation, GLUT4 translocates to the cell surface [reviewed in Ref. $(18,19)$ ]. In human glomeruli ex vivo, GLUT4 localizes in an intracellular vesicular distribution and at the apical and basolateral domains of the plasma membrane of the podocyte foot processes (10). Contrary to GLUT1, the expression of GLUT4 mRNA was shown to be upregulated in the glomeruli of normoalbuminuric T1DM patients (67), whereas glomeruli from T1DM patients with microalbuminuria presented decreased GLUT4 mRNA expression compared to non-diabetic controls (67). GLUT1 mRNA 
and protein expression followed a similar pattern in $\mathrm{db} / \mathrm{db}$ mice (67). Also, contrary to GLUT1, chronic exposure of cultured human podocytes to high glucose reduced GLUT4 expression (69). Interestingly, podocyte-specific GLUT4-deficient mice do not develop albuminuria even though they have fewer and larger podocytes than the wild-type mice (67). Furthermore, they are protected from diabetes-induced podocyte hypertrophy, mesangial expansion, and albuminuria (67). The mice showed increased activation of AMPK in glomeruli and suppression of the mammalian target of rapamycin (mTOR) pathway (67), proposing that lack of GLUT4 affects nutrient sensing in podocytes. Both clinical and experimental data support a role for nutrient sensing signals (mTORC1, AMPK) in the pathogenesis of the kidney complication in diabetes (76). AMPK activity has been shown to be decreased in the kidneys of several types of diabetic rodent models, including STZ-induced type 1 diabetic rats $(77,78)$ and type 2 diabetic $\mathrm{db} / \mathrm{db}$ mice $(79,80)$, leading to renal hypertrophy or renal interstitial fibrosis. Hyperactivation of the mTORC1 signal is strongly associated with the progression of podocyte injury and proteinuria in diabetic animal models, characterized by dysregulation of nephrin and podocyte loss $(39,81)$. These data suggest that high GLUT4 level would be an enemy in DKD and that decreasing GLUT4 expression or attenuating its function may be beneficial in diabetic kidney. Additional work is needed to investigate whether the function of GLUT4 in podocyte is independent of insulin signaling, as a study suggests that GLUT4 may directly regulate actin remodeling (82).

\section{Other GLUTs}

GLUT2 has been described to mediate glucose uptake in cultured rat podocytes (65). GLUT3 expression has been shown to be upregulated in human podocytes exposed to high glucose in vitro (69), and GLUT8 expression was higher in podocytes of kidneys of diabetic $\mathrm{db} / \mathrm{db}$ mice compared with non-diabetic mice (66). Defining the roles of these GLUTs in podocyte function awaits further studies in rodent models of diabetes and DKD.

\section{Properties of GLUTs and Metabolism of Podocytes}

GLUT1, GLUT3, GLUT4, and GLUT8 are high-affinity, lowcapacity GLUTs, and GLUT2 is a low-affinity, high-capacity GLUT (83). As individual transporters may get saturated, the presence of the high-affinity GLUTs at the plasma membrane plays an important role in regulating the flux of glucose into cells. As described earlier, the studies thus far have defined the expression of GLUT1 and GLUT4 only at the mRNA level in glomeruli of patients with diabetes (67), and the study defining their localization by immunoelectron microscopy in human podocytes concentrated looking at only normal human kidney tissue (10). It would be interesting to define the exact subcellular localization of each GLUT in podocytes during the progression of DKD, but this is challenging due to the invasiveness of obtaining tissue material. For the same reason, regulation of the metabolism of podocytes in diabetic conditions has mainly relied on studies carried out using cultured human podocytes treated with factors associated with diabetes. In line with this, during differentiation in normal $(5 \mathrm{mM})$ glucose, cultured human podocytes activate oxidative metabolism and reduce glycolytic enzymes (84). Hyperglycemic conditions ( $20 \mathrm{mM}$ glucose) promote metabolic reprogramming in podocytes, with reduction of mitochondrial biogenesis and increased glycolysis (84). Corresponding signs of glycolytic switch are observed in kidney sections of human patients with DKD (84). This is consistent with a previous study showing that mitochondrial function is dysregulated in patients with DKD (85).

\section{Molecular Regulators of GLUT Trafficking in Podocytes}

In the myoblasts and adipocytes in the basal state, at least half of the GLUT4 population is found in a vesicle compartment. Stimulation with insulin increases the amount of GLUT4 at the cell surface mainly by promoting exocytosis of GCVs and to a lesser extent by increasing exocytosis from the recycling system, orchestrated by an array of regulatory and sorting proteins $(10,86,87)$. In addition, glucose uptake into cells may be regulated by affecting the endocytosis of GLUT4 at the plasma membrane. Mechanisms that regulate GCV trafficking and glucose uptake into podocytes are less well defined than in adipocytes and myocytes, and currently there are no data describing the regulation of GLUT4 endocytosis in podocytes. Here, we summarize the current knowledge on the mechanisms by which sorting of GLUT4 into GCVs and insulin-stimulated GCV exocytosis are regulated in podocytes (Figure 2).

\section{Sorting}

Cultured podocytes depleted of CD2-associated protein show attenuated glucose uptake in the basal state compared with wildtype podocytes, and CD2AP knockout podocytes fail to increase glucose uptake in response to insulin (88). This process was found to be independent of the insulin signaling pathway (as measured by insulin-induced AKT activation) or altered expression of GLUT1 and GLUT4, proposing a defect in GLUT4 trafficking. In line with this, GLUT4 appears as clusters in the perinuclear region of podocytes lacking CD2AP (88). GLUT4 in the perinuclear region is sorted into GCVs prior to transport toward the plasma membrane (Figure 2). This step is controlled by GGA2, which facilitates the formation of GCVs by recruiting clathrin and adaptor proteins, leading to enhanced insulin-stimulated glucose uptake $(89,90)$. Of note, podocytes are the only cells in the kidney that express GGA2 (91). Interestingly, CD2AP forms a complex with GGA2, and the complex formation is further increased by insulin stimulation, proposing that $\mathrm{CD} 2 \mathrm{AP}$ regulates GCV sorting.

GGA2 binds a transmembrane protein, sortilin, a key component in the formation of GCVs (92). Sortilin overexpression stabilizes GLUT4 (92), and its upregulation in CD2AP-depleted podocytes could explain the increased protein level of GLUT4 (88). Sortilin overexpression has been shown to increase the efficiency of the formation of GCVs and to induce glucose uptake into adipocytes (92) and myocytes (93). Despite upregulation of GLUT4 and sortilin in the absence of CD2AP, GLUT4 was not efficiently trafficked to the plasma membrane in response to insulin (88). This suggests that increased expression of endogenous GLUT4 and sortilin in CD2AP knockout podocytes is a 


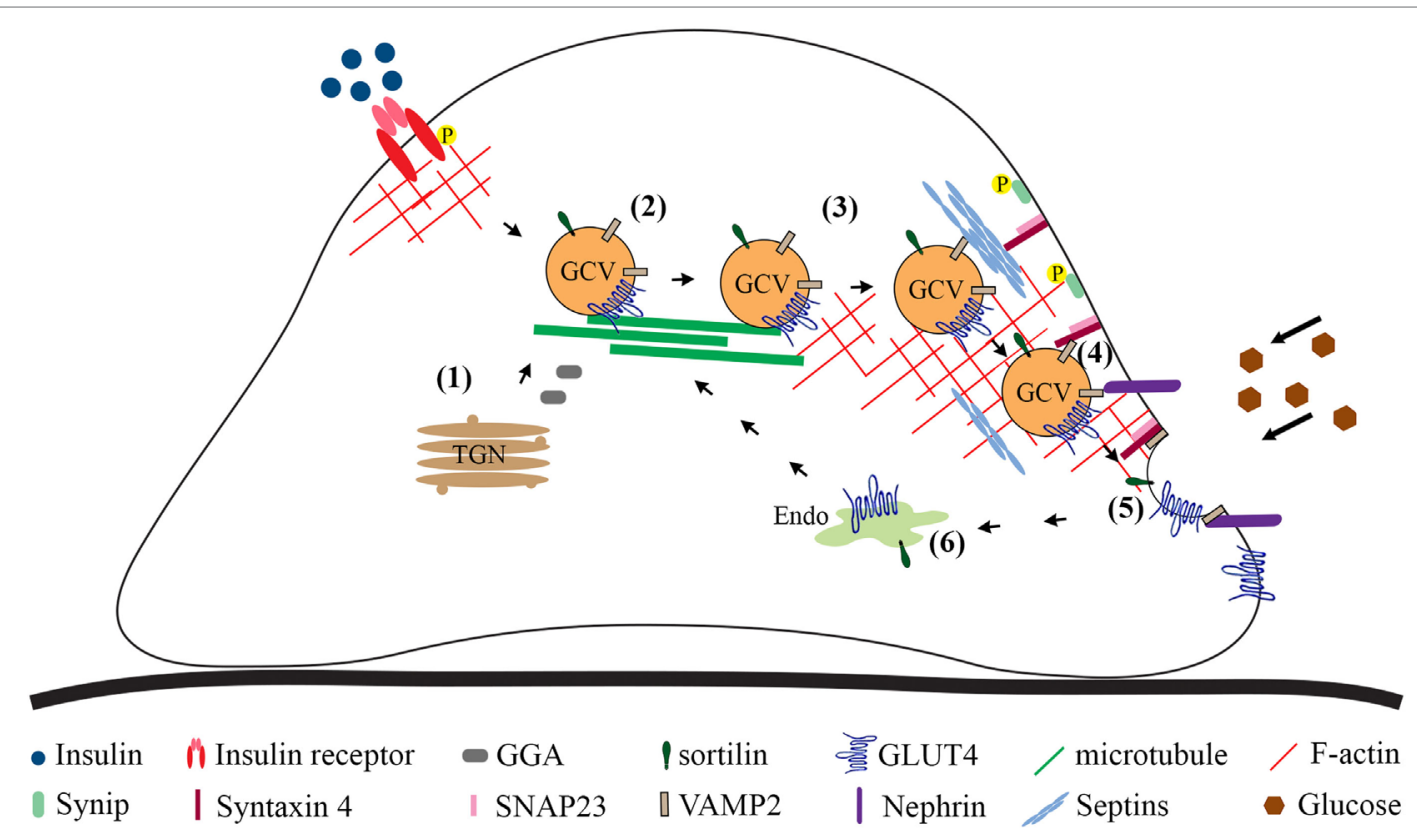

FIGURE 2 | Overview of the steps involved in GLUT4 trafficking to the plasma membrane based on studies carried out in cultured podocytes. Newly synthesized GLUT4 molecules are sorted directly into GCVs (1). GLUT4 may be sorted into GCVs also from other vesicular compartments. Cytoskeleton plays a role in approaching of the vesicles from the perinuclear region to the plasma membrane (2). Tethering (3), docking (4), and fusion (5) are required to merge the lipid bilayer of the GCV with the plasma membrane. Once at the plasma membrane, the GCV docking (4) and fusion (5) require formation of the ternary complex between V-SNARE, VAMP2, on the GCV and t-SNAREs, syntaxin-4 and SNAP23, on the plasma membrane, allowing the extracellular exposure of the GLUT4. (6) GLUT4 present at the plasma membrane is endocytosed and transported to the endosomal system for recycling. GCV, GLUT4-containing vesicle; P, phosphorylation; Endo, endosomes and recycling endosomes; TGN, trans-Golgi network; SNAP23, synaptosome-associated protein, 23 kDa; SNARE, N-ethylmaleimide-sensitive factor attachment protein receptor; t-SNARE, target SNARE; v-SNARE, vesicle SNARE; VAMP2, vesicle-associated membrane protein 2.

compensatory mechanism, possibly caused by a defect in GCV formation or trafficking. Interestingly, CD2AP forms a complex also with clathrin and, apparently via its ability to directly bind actin (94), connects clathrin to actin in the perinuclear region (88). When CD2AP is absent, the recycling of clathrin back to the trans-Golgi membranes from the vesicular fraction containing GCVs appears impaired. This reduces insulin-stimulated trafficking of GCVs resulting in reduced glucose uptake when CD2AP is absent (88).

\section{Approaching and Tethering}

The precise mechanism by which GCVs are delivered to the plasma membrane in podocytes is not well defined, but it has been shown that the translocation depends on an intact actin cytoskeleton $(10,26)$. Insulin-treated podocytes display cortical reorganization of actin, which occurs via activation of RhoA and inhibition of $\operatorname{CDC} 42(10,26)$. Also ezrin, an actin-binding protein, induces dynamic remodeling of actin in podocytes and the process involves the actin-severing protein cofilin-1 (95). Loss of ezrin in cultured podocytes increases glucose uptake, but apparently this does not occur due to enhanced trafficking of GLUT4. In response to insulin, podocytes absorb glucose not only via GLUT4 but also via the constitutive GLUT, GLUT1 (10). In ezrin-depleted podocytes, GLUT1 was observed at the plasma membrane in basal, starved, and insulin-stimulated conditions, proposing that an increase in glucose uptake in ezrin-deficient podocytes is due to enhanced trafficking of GLUT1 to the plasma membrane (95). Interestingly, ezrin is downregulated in the glomeruli of obese Zucker rats and in podocytes of human patients with T2DM without clinical nephropathy or histopathological diagnostic signs of DN (95). The effect of ezrin downregulation on GLUTs and glucose uptake in the glomeruli in vivo awaits further studies.

\section{Docking and Fusion}

The final step of the GCV trafficking requires docking and fusion machinery that merges the lipid bilayer of the GCV with that of the plasma membrane. The SD protein nephrin plays an important role in this process, as podocytes deficient in nephrin or with missense mutations in nephrin are insensitive to insulin with respect to glucose uptake (96). Nephrin interacts with several key regulators of GLUT4 trafficking, including the vesicle-associated VAMP2 on GCVs, and facilitates the insulinstimulated GCV fusion with the plasma membrane (96). Nephrin also forms a complex with the small filamentous GTPase septin 7, which negatively regulates glucose uptake into podocytes (97). Knockdown of septin 7 strengthens the interaction between nephrin and VAMP2 and also between syntaxin 4 and VAMP2 (97) (Figure 2). This, supported by the previous models proposed for septin-5/CDCrel-1 (98), corroborates the idea that septin 7 forms a physical barrier that hinders GCV trafficking. Thereby, depletion of septin 7 allows the SNARE complex formation between the v-SNAREs and the plasma membrane-SNAREs (97) (Figure 2). Nucleobindin-2 was recently shown to associate with 
septin 7 (99). As knockdown of nucleobindin-2 prevents insulinstimulated translocation of GLUT4 to the plasma membrane, the authors suggested that nucleobindin-2 may reverse septin 7-induced inhibition of insulin-stimulated GLUT4 translocation in podocytes (99). This, however, requires detailed studies to define whether nucleobinding-2 functionally affects septin 7 and to unravel the molecular mechanisms involved.

It is plausible to assume that certain proteins that regulate GLUT4 trafficking in muscle and adipose cells function similarly in podocytes. One such protein is syntaxin 4-interacting protein (synip), which regulates the docking and fusion of GCVs with the plasma membrane in adipocytes (100). Synip occupies the same binding domain on syntaxin 4 that also interacts with VAMP2. Insulin induces phosphorylation of synip on S99, which leads to dissociation of synip from syntaxin 4 , thereby vacating the binding site for VAMP2 and allowing the fusion to occur (100) (Figure 2). In line with this, GCVs in podocytes expressing a phosphorylation-deficient Synip mutant (S99A) fail to dock and fuse with the plasma membrane and the cells present with reduced glucose uptake (101).

Another protein that has been shown to regulate glucose uptake in both adipocytes and podocytes is non-muscle myosin IIA (NM-IIA) (102-104). Knockdown of non-muscle myosin heavy chain IIA (NMHC-IIA), a component of the NM-IIA hexameric complex, decreases insulin-stimulated glucose uptake into podocytes (104). Insulin stimulation activates NM-IIA by phosphorylating the regulatory light chain subunit of the complex, and this enhances GCV docking and fusion with the plasma membrane (103). Interestingly, nephrin, septin 7, and the plasma membrane SNARE protein SNAP23 form a complex with NMHC-IIA (104). Septin 7 is a regulator of the NM-IIA activity in the SNAP23 complex, as knockdown of septin 7 enhances the phosphorylation of the NM-IIA regulatory light chain in the SNAP23 complex. In line with this, insulin stimulation is coupled with a decrease in septin 7 level and an increase in the activity of NM-IIA in the SNAP23 complex, enhancing GCV docking and fusion and increasing glucose uptake into podocytes (104). Thus, in addition to forming a physical barrier, septin 7 reduces glucose uptake into podocytes by reducing the activity of NM-IIA in the plasma membrane SNARE complex. In diabetic rat glomeruli and cultured human podocytes exposed to macroalbuminuric sera from patients with T1DM, the activity of NM-IIA is increased (104), potentially leading to an increase in glucose uptake.

\section{INSULIN RESISTANCE ASSOCIATES WITH THE DEVELOPMENT OF DKD}

\footnotetext{
Mechanisms Leading to Insulin Resistance

Insulin resistance is a condition in which cells fail to respond to the normal actions of insulin. At the cellular level, the mechanisms leading to the development of insulin resistance may include mutations in the IR itself, impairments in the PI3K/ AKT signaling pathway or perturbations in the GLUT trafficking. These changes may lead to reduced uptake of glucose into cells and contribute to the development of hyperglycemia.
}

Several pieces of evidence suggest that reduced action of insulin may play a role in the development of DKD. Insulin resistance has been reported to correlate with microalbuminuria in patients with T1DM (4) or T2DM (5-7) and also in non-diabetic subjects (8). Both clinical and experimental data suggest that insulin sensitizers have a renoprotective role in patients with diabetes (105) as well as in experimental animal models of diabetes $(73,106,107)$. Interestingly, podocytes are insulin sensitive and share similarities with skeletal muscle cells and adipocytes in respect to the kinetics of the insulin-stimulated glucose uptake and the expression of GLUTs, including GLUT1 and GLUT4 (10). Due to the invasiveness, it is challenging to define whether podocytes in human patients with diabetes develop insulin resistance and to determine whether podocyte insulin resistance per se contributes to the development of DKD. Identification of normoglycemic, insulin-resistant patients presenting DKD support the role of insulin resistance as a contributing factor in the pathogenesis of DKD, as described in a recent case report (108). However, these cases are apparently few, suggesting that insulin resistance alone is not enough to lead to the development of DKD. Also, only some of the patients with mutations in IR and severe insulin resistance develop DKD, and some develop other kidney diseases (109), suggesting that insulin resistance, in combination with other factors, may contribute to kidney injury. A recent review summarizes the consequences of insulin resistance and the potential mechanisms associated with the progression of DKD (12). These data highlight the importance of understanding the mechanisms by which insulin sensitivity of podocytes is regulated and helps to identify new targets and define new treatment strategies for kidney diseases involving insulin resistance.

\section{FACTORS REGULATING GLUTS AND THEIR TRAFFICKING IN PODOCYTES}

Insulin signaling in podocytes is influenced by various factors and has been reviewed elsewhere $(13,110)$. Here, we shortly summarize diabetes-associated external factors shown to influence GLUTs and their trafficking (Figure 3).

In diabetes, podocytes are exposed to high glucose concentrations prompting to carry out analyses on the effect of high glucose on the expression of GLUTs. High glucose treatment of cultured human podocytes led to the upregulation of GLUT1 and GLUT3 and downregulation of GLUT4 (69). In addition, high glucose increased the presence of GLUT1, but not of GLUT3 or GLUT4, at the plasma membrane (69). Another study defined the effect of mechanical stress, modulating increased intracapillary pressure observed in diabetes, in combination with high glucose on glucose uptake using cultured rat podocytes (111). The study revealed that mechanical stress increased glucose uptake, and the effect was potentiated by high glucose. The combination of high glucose and mechanical stress decreased the expression of both GLUT2 and GLUT4 at the plasma membrane, suggesting that the increase in glucose uptake is mediated by other GLUTs under these conditions (111). 


\section{MECHANICAL STRESS}

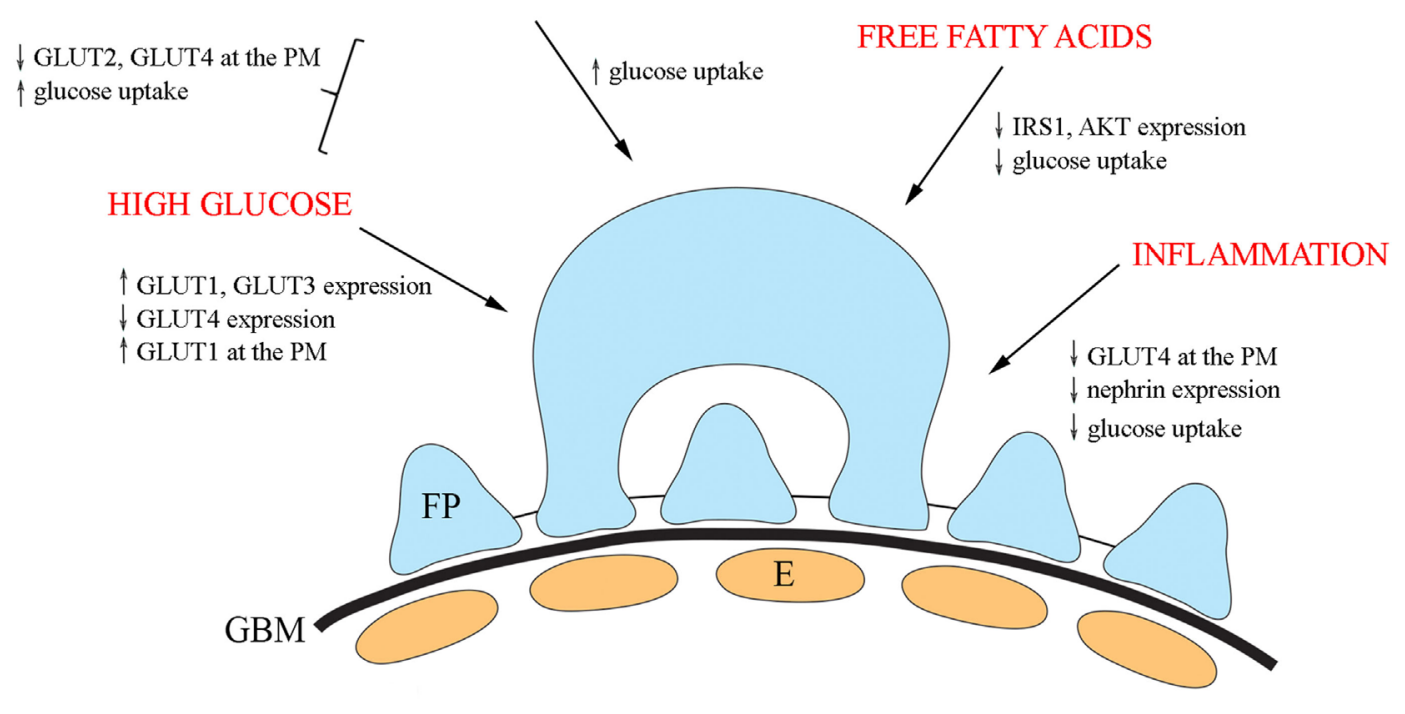

FIGURE 3 | An overview of the diabetes-associated external factors regulating glucose transporters and glucose uptake in podocytes. In cultured podocytes, high glucose leads to upregulation of GLUT1 and GLUT3 and downregulation of GLUT4 and increases the presence of GLUT1 at the plasma membrane. Mechanical stress increases glucose uptake and in combination with high glucose, decreases the expression of both GLUT2 and GLUT4 at the plasma membrane, and increases glucose uptake. Free fatty acids lead to reduced phosphorylation of IRS1 and AKT and diminished glucose uptake. Also, inflammatory mechanisms impair insulin signaling and insulin-induced glucose uptake in cultured podocytes. E, endothelial cell; FP, foot process; GBM, glomerular basement membrane.

Of obesity and insulin resistance-associated factors, free fatty acids play a central role in the progression of T2DM. Treatment of cultured human podocytes with palmitate, the predominant circulating saturated free fatty acid, leads to reduced phosphorylation of IRS1 and AKT and diminished glucose uptake (112). An increasing number of studies indicate that activation of the innate immune system, and inflammatory mechanisms are important in the pathogenesis of DKD (113-117). Nucleotidebinding oligomerization domain containing 2 (NOD2), a member of the NOD-like receptor family, plays an important role in innate immune response and has been shown to be upregulated in the kidney in an experimental model and patients with diabetes (118). In line with this, depletion of NOD2 was found to protect against diabetes-induced kidney injury. NOD2 was further observed to impair insulin signaling and insulin-induced glucose uptake in cultured podocytes by inhibiting GLUT4 translocation to the plasma membrane (118). Knockdown of NOD2 expression also attenuated nephrin downregulation induced by high glucose. This is of importance in the context that nephrin enhances GCV docking and fusion with the plasma membrane (96). Interestingly, also activated macrophages downregulate nephrin expression via TNF $\alpha$ and induce podocyte injury (119).

\section{CONCLUSION}

Diabetic kidney disease is the leading cause of end-stage renal disease worldwide. Treatments targeting hyperglycemia and blood pressure combined with lifestyle interventions have not been able to stop the progression of this devastating disease.
This calls for continued research on the pathophysiological mechanisms associated with the progression of $\mathrm{DKD}$, aiming to identify new targets for drug development. Studies have shown that insulin-sensitizing agents, including metformin and PPAR $\gamma$ agonists, are beneficial in preventing kidney damage in both T1DM (120) and T2DM (121) as well as in non-DKD (122). $\operatorname{PPAR} \gamma$ agonist rosiglitazone enhances glucose uptake into podocytes by enhancing GLUT1 translocation to the plasma membrane (75), and remarkably, GLUT1 overexpression in podocytes protects against DKD (72). Concomitantly, proteins that enhance the presence of GLUT1 at the plasma membrane could have therapeutic potential in preventing the development and progression of DKD.

Interestingly, research has revealed that molecules associated with insulin signaling and glucose uptake in podocytes have importance in a context wider than just glucose uptake. Accordingly, GLUT4 plays a role in podocyte nutrient sensing, and interestingly, depletion of GLUT4 protects podocytes from DKD by reducing mTOR signaling (67). In addition to mTOR, nutrient-sensing signals AMPK and Sirt1 are altered in the diabetic kidney [reviewed in Ref. (76)]. Autophagic activity, which is regulated by the above-mentioned nutrient-sensing signals, is also altered in both podocytes and proximal tubular cells under diabetic conditions $(123,124)$. This proposes that molecules that reduce the expression or functional activity of GLUT4 or affect the nutrient sensing pathways in podocytes could provide potential treatment targets in $\mathrm{DKD}$. In the next few years, additional studies addressing these pathways as well as defining the functions of other, thus far less studied GLUTs, 
GLUT2, GLUT3, and GLUT8, in podocytes and potentially elsewhere in the nephron, may ultimately provide a clearer perspective for the development of new drugs. The new roles may include, in addition to the expected functions in glucose uptake, novel functional indications and pathways independent of insulin signaling and glucose uptake. Finally, it will be important to define the functional interplay between the various pathways to elucidate the regulatory networks that maintain the normal function of podocytes in health or when disturbed and lead to podocyte dysfunction and development of albuminuria.

\section{REFERENCES}

1. Harjutsalo V, Groop PH. Epidemiology and risk factors for diabetic kidney disease. Adv Chronic Kidney Dis (2014) 21:260-6. doi:10.1053/j. ackd.2014.03.009

2. Adler AI, Stevens RJ, Manley SE, Bilous RW, Cull CA, Holman RR, et al. Development and progression of nephropathy in type 2 diabetes: the United Kingdom Prospective Diabetes Study (UKPDS 64). Kidney Int (2003) 63:225-32. doi:10.1046/j.1523-1755.2003.00712.x

3. Welsh GI, Coward RJ. Podocytes, glucose and insulin. Curr Opin Nephrol Hypertens (2010) 19:379-84. doi:10.1097/MNH.0b013e32833ad5e4

4. Yip J, Mattock MB, Morocutti A, Sethi M, Trevisan R, Viberti G. Insulin resistance in insulin-dependent diabetic patients with microalbuminuria. Lancet (1993) 342:883-7. doi:10.1016/0140-6736(93)91943-G

5. Groop L, Ekstrand A, Forsblom C, Widen E, Groop PH, Teppo AM, et al. Insulin resistance, hypertension and microalbuminuria in patients with type 2 (non-insulin-dependent) diabetes mellitus. Diabetologia (1993) 36:642-7. doi:10.1007/BF00400814

6. Forsblom CM, Eriksson JG, Ekstrand AV, Teppo AM, Taskinen MR, Groop LC. Insulin resistance and abnormal albumin excretion in non-diabetic first-degree relatives of patients with NIDDM. Diabetologia (1995) 38:363-9. doi:10.1007/BF00400643

7. Parvanova AI, Trevisan R, Iliev IP, Dimitrov BD, Vedovato M, Tiengo A, et al. Insulin resistance and microalbuminuria: a cross-sectional, case-control study of 158 patients with type 2 diabetes and different degrees of urinary albumin excretion. Diabetes (2006) 55:1456-62. doi:10.2337/db05-1484

8. Mykkanen L, Zaccaro DJ, Wagenknecht LE, Robbins DC, Gabriel M, Haffner SM. Microalbuminuria is associated with insulin resistance in nondiabetic subjects: the insulin resistance atherosclerosis study. Diabetes (1998) 47:793-800. doi:10.2337/diabetes.47.5.793

9. Wolf G, Chen S, Ziyadeh FN. From the periphery of the glomerular capillary wall toward the center of disease: podocyte injury comes of age in diabetic nephropathy. Diabetes (2005) 54:1626-34. doi:10.2337/diabetes.54.6.1626

10. Coward RJ, Welsh GI, Yang J, Tasman C, Lennon R, Koziell A, et al. The human glomerular podocyte is a novel target for insulin action. Diabetes (2005) 54:3095-102. doi:10.2337/diabetes.54.11.3095

11. Tejada T, Catanuto P, Ijaz A, Santos JV, Xia X, Sanchez P, et al. Failure to phosphorylate AKT in podocytes from mice with early diabetic nephropathy promotes cell death. Kidney Int (2008) 73:1385-93. doi:10.1038/ki.2008.109

12. Gnudi L, Coward RJM, Long DA. Diabetic nephropathy: perspective on novel molecular mechanisms. Trends Endocrinol Metab (2016) 27:820-30. doi:10.1016/j.tem.2016.07.002

13. Lay A, Coward RJ. Recent advances in our understanding of insulin signalling to the podocyte. Nephrol Dial Transplant (2014) 29:1127-33. doi:10.1093/ ndt/gft471

14. Coward R, Fornoni A. Insulin signaling: implications for podocyte biology in diabetic kidney disease. Curr Opin Nephrol Hypertens (2015) 24:104-10. doi:10.1097/mnh.0000000000000078

15. Lee J, Pilch PF. The insulin receptor: structure, function, and signaling. Am J Physiol (1994) 266:C319-34. doi:10.1152/aipcell.1994.266.2.C319

16. Belfiore A, Frasca F, Pandini G, Sciacca L, Vigneri R. Insulin receptor isoforms and insulin receptor/insulin-like growth factor receptor hybrids

\section{AUTHOR CONTRIBUTIONS}

AW and SL contributed to conception and design, performed literature searches, and wrote the manuscript.

\section{ACKNOWLEDGMENTS}

This work was supported by Jane and Aatos Erkko Foundation (SL), the EFSD/Boehringer Ingelheim Research programme (SL), and HiLife, University of Helsinki (SL). Eero Lehtonen (University of Helsinki) is acknowledged for the electron microscopic image.

in physiology and disease. Endocr Rev (2009) 30:586-623. doi:10.1210/ er.2008-0047

17. Ullrich A, Bell JR, Chen EY, Herrera R, Petruzzelli LM, Dull TJ, et al. Human insulin receptor and its relationship to the tyrosine kinase family of oncogenes. Nature (1985) 313:756-61. doi:10.1038/313756a0

18. Stockli J, Fazakerley DJ, James DE. GLUT4 exocytosis. J Cell Sci (2011) 124:4147-59. doi:10.1242/jcs.097063

19. Jaldin-Fincati JR, Pavarotti M, Frendo-Cumbo S, Bilan PJ, Klip A. Update on GLUT4 vesicle traffic: a cornerstone of insulin action. Trends Endocrino Metab (2017) 28:597-611. doi:10.1016/j.tem.2017.05.002

20. Shepherd PR. Mechanisms regulating phosphoinositide 3-kinase signalling in insulin-sensitive tissues. Acta Physiol Scand (2005) 183:3-12. doi:10.1111/j. 1365-201X.2004.01382.x

21. Liu J, Kimura A, Baumann CA, Saltiel AR. APS facilitates c-Cbl tyrosine phosphorylation and GLUT4 translocation in response to insulin in 3T3-L1 adipocytes. Mol Cell Biol (2002) 22:3599-609. doi:10.1128/ MCB.22.11.3599-3609.2002

22. Chiang SH, Baumann CA, Kanzaki M, Thurmond DC, Watson RT, Neudauer CL, et al. Insulin-stimulated GLUT4 translocation requires the CAP-dependent activation of TC10. Nature (2001) 410:944-8. doi: $10.1038 / 35073608$

23. Inoue M, Chang L, Hwang J, Chiang SH, Saltiel AR. The exocyst complex is required for targeting of Glut4 to the plasma membrane by insulin. Nature (2003) 422:629-33. doi:10.1038/nature01533

24. Ewart MA, Clarke M, Kane S, Chamberlain LH, Gould GW. Evidence for a role of the exocyst in insulin-stimulated Glut4 trafficking in 3T3-L1 adipocytes. J Biol Chem (2005) 280:3812-6. doi:10.1074/jbc.M409928200

25. Tokhtaeva E, Capri J, Marcus EA, Whitelegge JP, Khuzakhmetova V, Bukharaeva E, et al. Septin dynamics are essential for exocytosis. J Biol Chem (2015) 290:5280-97. doi:10.1074/jbc.M114.616201

26. Welsh GI, Hale LJ, Eremina V, Jeansson M, Maezawa Y, Lennon R, et al. Insulin signaling to the glomerular podocyte is critical for normal kidney function. Cell Metab (2010) 12:329-40. doi:10.1016/j.cmet.2010.08.015

27. Santamaria B, Marquez E, Lay A, Carew RM, Gonzalez-Rodriguez A, Welsh GI, et al. IRS2 and PTEN are key molecules in controlling insulin sensitivity in podocytes. Biochim Biophys Acta (2015) 1853:3224-34. doi:10.1016/j. bbamcr.2015.09.020

28. Mima A, Ohshiro Y, Kitada M, Matsumoto M, Geraldes P, Li C, et al. Glomerular-specific protein kinase C-beta-induced insulin receptor substrate-1 dysfunction and insulin resistance in rat models of diabetes and obesity. Kidney Int (2011) 79:883-96. doi:10.1038/ki.2010.526

29. Katsoulieris EN, Drossopoulou GI, Kotsopoulou ES, Vlahakos DV, Lianos EA, Tsilibary EC. High glucose impairs insulin signaling in the glomerulus: an in vitro and ex vivo approach. PLoS One (2016) 11:e0158873. doi:10.1371/ journal.pone. 0158873

30. Ruotsalainen V, Ljungberg P, Wartiovaara J, Lenkkeri U, Kestila M, Jalanko H, et al. Nephrin is specifically located at the slit diaphragm of glomerular podocytes. Proc Natl Acad Sci U S A (1999) 96:7962-7. doi:10.1073/ pnas.96.14.7962

31. Shih NY, Li J, Cotran R, Mundel P, Miner JH, Shaw AS. CD2AP localizes to the slit diaphragm and binds to nephrin via a novel C-terminal domain. Am J Pathol (2001) 159:2303-8. doi:10.1016/s0002-9440(10)63080-5 
32. Jones N, Blasutig IM, Eremina V, Ruston JM, Bladt F, Li H, et al. Nck adaptor proteins link nephrin to the actin cytoskeleton of kidney podocytes. Nature (2006) 440:818-23. doi:10.1038/nature04662

33. Zhu J, Sun N, Aoudjit L, Li H, Kawachi H, Lemay S, et al. Nephrin mediates actin reorganization via phosphoinositide 3-kinase in podocytes. Kidney Int (2008) 73:556-66. doi:10.1038/sj.ki.5002691

34. Huber TB, Hartleben B, Kim J, Schmidts M, Schermer B, Keil A, et al. Nephrin and $\mathrm{CD} 2 \mathrm{AP}$ associate with phosphoinositide 3-OH kinase and stimulate AKT-dependent signaling. Mol Cell Biol (2003) 23:4917-28. doi:10.1128/ MCB.23.14.4917-4928.2003

35. Doublier S, Salvidio G, Lupia E, Ruotsalainen V, Verzola D, Deferrari G, et al. Nephrin expression is reduced in human diabetic nephropathy: evidence for a distinct role for glycated albumin and angiotensin II. Diabetes (2003) 52:1023-30. doi:10.2337/diabetes.52.4.1023

36. Jim B, Ghanta M, Qipo A, Fan Y, Chuang PY, Cohen HW, et al. Dysregulated nephrin in diabetic nephropathy of type 2 diabetes: a cross sectional study. PLoS One (2012) 7:e36041. doi:10.1371/journal.pone.0036041

37. Bonnet F, Cooper ME, Kawachi H, Allen TJ, Boner G, Cao Z. Irbesartan normalises the deficiency in glomerular nephrin expression in a model of diabetes and hypertension. Diabetologia (2001) 44:874-7. doi:10.1007/ s001250100546

38. Hyvonen ME, Dumont V, Tienari J, Lehtonen E, Ustinov J, Havana M, et al. Early-onset diabetic E1-DN mice develop albuminuria and glomerular injury typical of diabetic nephropathy. Biomed Res Int (2015) 2015:102969. doi:10.1155/2015/102969

39. Inoki K, Mori H, Wang J, Suzuki T, Hong S, Yoshida S, et al. mTORC1 activation in podocytes is a critical step in the development of diabetic nephropathy in mice. J Clin Invest (2011) 121:2181-96. doi:10.1172/jci44771

40. Dumont V, Tolvanen TA, Kuusela S, Wang H, Nyman TA, Lindfors S, et al. PACSIN2 accelerates nephrin trafficking and is up-regulated in diabetic kidney disease. FASEB J (2017) 31:3978-90. doi:10.1096/fj.201601265R

41. Vinciguerra M, Foti M. PTEN and SHIP2 phosphoinositide phosphatases as negative regulators of insulin signalling. Arch Physiol Biochem (2006) 112:89-104. doi:10.1080/13813450600711359

42. Pesesse X, Deleu S, De Smedt F, Drayer L, Erneux C. Identification of a second $\mathrm{SH} 2$-domain-containing protein closely related to the phosphatidylinositol polyphosphate 5-phosphatase SHIP. Biochem Biophys Res Commun (1997) 239:697-700. doi:10.1006/bbrc.1997.7538

43. Hyvonen ME, Saurus P, Wasik A, Heikkila E, Havana M, Trokovic R, et al. Lipid phosphatase SHIP2 downregulates insulin signalling in podocytes. Mol Cell Endocrinol (2010) 328:70-9. doi:10.1016/j.mce.2010.07.016

44. Rogacka D, Piwkowska A, Audzeyenka I, Angielski S, Jankowski M. Involvement of the AMPK-PTEN pathway in insulin resistance induced by high glucose in cultured rat podocytes. Int J Biochem Cell Biol (2014) 51:120-30. doi:10.1016/j.biocel.2014.04.008

45. Drapeau N, Lizotte F, Denhez B, Guay A, Kennedy CR, Geraldes P. Expression of SHP-1 induced by hyperglycemia prevents insulin actions in podocytes. Am JPhysiol Endocrinol Metab (2013) 304:E1188-98. doi:10.1152/ ajpendo.00560.2012

46. Ijaz A, Tejada T, Catanuto P, Xia X, Elliot SJ, Lenz O, et al. Inhibition of C-jun $\mathrm{N}$-terminal kinase improves insulin sensitivity but worsens albuminuria in experimental diabetes. Kidney Int (2009) 75:381-8. doi:10.1038/ki.2008.559

47. Bergandi L, Silvagno F, Russo I, Riganti C, Anfossi G, Aldieri E, et al. Insulin stimulates glucose transport via nitric oxide/cyclic GMP pathway in human vascular smooth muscle cells. Arterioscler Thromb Vasc Biol (2003) 23:2215-21. doi:10.1161/01.ATV.0000107028.20478.8e

48. Richie-Jannetta R, Francis SH, Corbin JD. Dimerization of cGMP-dependent protein kinase Ibeta is mediated by an extensive amino-terminal leucine zipper motif, and dimerization modulates enzyme function. J Biol Chem (2003) 278:50070-9. doi:10.1074/jbc.M306796200

49. Piwkowska A, Rogacka D, Angielski S, Jankowski M. Insulin stimulates glucose transport via protein kinase $G$ type I alpha-dependent pathway in podocytes. Biochem Biophys Res Commun (2014) 446:328-34. doi:10.1016/j. bbrc.2014.02.108

50. Rogacka D, Audzeyenka I, Rachubik P, Rychlowski M, Kasztan M, Jankowski M, et al. Insulin increases filtration barrier permeability via TRPC6-dependent activation of PKGIalpha signaling pathways. Biochim Biophys Acta (2017) 1863:1312-25. doi:10.1016/j.bbadis.2017.03.002
51. Piwkowska A, Rogacka D, Kasztan M, Angielski S, Jankowski M. Insulin increases glomerular filtration barrier permeability through dimerization of protein kinase G type Ialpha subunits. Biochim Biophys Acta (2013) 1832:791-804. doi:10.1016/j.bbadis.2013.02.011

52. Piwkowska A, Rogacka D, Jankowski M, Kocbuch K, Angielski S. Hydrogen peroxide induces dimerization of protein kinase $\mathrm{G}$ type Ialpha subunits and increases albumin permeability in cultured rat podocytes. J Cell Physiol (2012) 227:1004-16. doi:10.1002/jcp.22810

53. Byers MS, Howard C, Wang X. Avian and mammalian facilitative glucose transporters. Microarrays (Basel) (2017) 6:E7. doi:10.3390/ microarrays 6020007

54. Chiu TT, Jensen TE, Sylow L, Richter EA, Klip A. Rac1 signalling towards GLUT4/glucose uptake in skeletal muscle. Cell Signal (2011) 23:1546-54. doi:10.1016/j.cellsig.2011.05.022

55. Tunduguru R, Thurmond DC. Promoting glucose transporter-4 vesicle trafficking along cytoskeletal tracks: PAK-Ing them out. Front Endocrinol (2017) 8:329. doi:10.3389/fendo.2017.00329

56. Omata W, Shibata H, Li L, Takata K, Kojima I. Actin filaments play a critical role in insulin-induced exocytotic recruitment but not in endocytosis of GLUT4 in isolated rat adipocytes. Biochem $J$ (2000) 346(Pt 2):321-8. doi:10.1042/bj3460321

57. Tong P, Khayat ZA, Huang C, Patel N, Ueyama A, Klip A. Insulin-induced cortical actin remodeling promotes GLUT4 insertion at muscle cell membrane ruffles. J Clin Invest (2001) 108:371-81. doi:10.1172/jci12348

58. Kanzaki M, Pessin JE. Insulin-stimulated GLUT4 translocation in adipocytes is dependent upon cortical actin remodeling. J Biol Chem (2001) 276:42436-44. doi:10.1074/jbc.M108297200

59. Foster LJ, Klip A. Mechanism and regulation of GLUT-4 vesicle fusion in muscle and fat cells. Am J Physiol Cell Physiol (2000) 279:C877-90. doi:10.1152/ajpcell.2000.279.4.C877

60. Watson RT, Kanzaki M, Pessin JE. Regulated membrane trafficking of the insulin-responsive glucose transporter 4 in adipocytes. Endocr Rev (2004) 25:177-204. doi:10.1210/er.2003-0011

61. Sollner TH. Regulated exocytosis and SNARE function (review). Mol Membr Biol (2003) 20:209-20. doi:10.1080/0968768031000104953

62. Rothman JE. Intracellular membrane fusion. Adv Second Messenger Phosphoprotein Res (1994) 29:81-96. doi:10.1016/S1040-7952(06)80008-X

63. Weber T, Zemelman BV, McNew JA, Westermann B, Gmachl M, Parlati F, et al. SNAREpins: minimal machinery for membrane fusion. Cell (1998) 92:759-72. doi:10.1016/S0092-8674(00)81404-X

64. Heilig C, Zaloga C, Lee M, Zhao X, Riser B, Brosius F, et al. Immunogold localization of high-affinity glucose transporter isoforms in normal rat kidney. Lab Invest (1995) 73:674-84

65. Lewko B, Bryl E, Witkowski JM, Latawiec E, Golos M, Endlich N, et al. Characterization of glucose uptake by cultured rat podocytes. Kidney Blood Press Res (2005) 28:1-7. doi:10.1159/000080889

66. Schiffer M, Susztak K, Ranalletta M, Raff AC, Bottinger EP, Charron MJ. Localization of the GLUT8 glucose transporter in murine kidney and regulation in vivo in nondiabetic and diabetic conditions. Am J Physiol Renal Physiol (2005) 289:F186-93. doi:10.1152/ajprenal.00234.2004

67. Guzman J, Jauregui AN, Merscher-Gomez S, Maiguel D, Muresan C, Mitrofanova A, et al. Podocyte-specific GLUT4-deficient mice have fewer and larger podocytes and are protected from diabetic nephropathy. Diabetes (2014) 63:701-14. doi:10.2337/db13-0752

68. D’Agord Schaan B, Lacchini S, Bertoluci MC, Irigoyen MC, Machado UF, Schmid H. Increased renal GLUT1 abundance and urinary TGF-beta 1 in streptozotocin-induced diabetic rats: implications for the development of nephropathy complicating diabetes. Horm Metab Res (2001) 33:664-9. doi:10.1055/s-2001-18683

69. Moutzouris DA, Kitsiou PV, Talamagas AA, Drossopoulou GI, Kassimatis TI, Katsilambros NK. Chronic exposure of human glomerular epithelial cells to high glucose concentration results in modulation of high-affinity glucose transporters expression. Ren Fail (2007) 29:353-8. doi:10.1080/ 08860220601184126

70. Heilig CW, Liu Y, England RL, Freytag SO, Gilbert JD, Heilig KO, et al. D-glucose stimulates mesangial cell GLUT1 expression and basal and IGFI-sensitive glucose uptake in rat mesangial cells: implications for diabetic nephropathy. Diabetes (1997) 46:1030-9. doi:10.2337/diab.46.6.1030 
71. Wang Y, Heilig K, Saunders T, Minto A, Deb DK, Chang A, et al. Transgenic overexpression of GLUT1 in mouse glomeruli produces renal disease resembling diabetic glomerulosclerosis. Am J Physiol Renal Physiol (2010) 299:F99-111. doi:10.1152/ajprenal.00466.2009

72. Zhang H, Schin M, Saha J, Burke K, Holzman LB, Filipiak W, et al. Podocytespecific overexpression of GLUT1 surprisingly reduces mesangial matrix expansion in diabetic nephropathy in mice. Am J Physiol Renal Physiol (2010) 299:F91-8. doi:10.1152/ajprenal.00021.2010

73. Zhang H, Saha J, Byun J, Schin M, Lorenz M, Kennedy RT, et al. Rosiglitazone reduces renal and plasma markers of oxidative injury and reverses urinary metabolite abnormalities in the amelioration of diabetic nephropathy. Am J Physiol Renal Physiol (2008) 295:F1071-81. doi:10.1152/ajprenal. 90208.2008

74. Bakris G, Viberti G, Weston WM, Heise M, Porter LE, Freed MI. Rosiglitazone reduces urinary albumin excretion in type II diabetes. J Hum Hypertens (2003) 17:7-12. doi:10.1038/sj.jhh.1001444

75. Lennon R, Welsh GI, Singh A, Satchell SC, Coward RJ, Tavare JM, et al. Rosiglitazone enhances glucose uptake in glomerular podocytes using the glucose transporter GLUT1. Diabetologia (2009) 52:1944-52. doi:10.1007/ s00125-009-1423-7

76. Kume S, Thomas MC, Koya D. Nutrient sensing, autophagy, and diabetic nephropathy. Diabetes (2012) 61:23-9. doi:10.2337/db11-0555

77. Ha TS, Park HY, Nam JA, Han GD. Diabetic conditions modulate the adenosine monophosphate-activated protein kinase of podocytes. Kidney Res Clin Pract (2014) 33:26-32. doi:10.1016/j.krcp.2014.02.001

78. Lee MJ, Feliers D, Mariappan MM, Sataranatarajan K, Mahimainathan L, Musi N, et al. A role for AMP-activated protein kinase in diabetes-induced renal hypertrophy. Am J Physiol Renal Physiol (2007) 292:F617-27. doi:10.1152/ajprenal.00278.2006

79. Kitada M, Kume S, Imaizumi N, Koya D. Resveratrol improves oxidative stress and protects against diabetic nephropathy through normalization of Mn-SOD dysfunction in AMPK/SIRT1-independent pathway. Diabetes (2011) 60:634-43. doi:10.2337/db10-0386

80. He T, Xiong J, Nie L, Yu Y, Guan X, Xu X, et al. Resveratrol inhibits renal interstitial fibrosis in diabetic nephropathy by regulating AMPK/ NOX4/ROS pathway. J Mol Med (Berl) (2016) 94:1359-71. doi:10.1007/ s00109-016-1451-y

81. Godel M, Hartleben B, Herbach N, Liu S, Zschiedrich S, Lu S, et al. Role of mTOR in podocyte function and diabetic nephropathy in humans and mice. J Clin Invest (2011) 121:2197-209. doi:10.1172/jci44774

82. Kao AW, Noda Y, Johnson JH, Pessin JE, Saltiel AR. Aldolase mediates the association of F-actin with the insulin-responsive glucose transporter GLUT4. J Biol Chem (1999) 274:17742-7. doi:10.1074/jbc.274.25.17742

83. Zhao FQ, Keating AF. Functional properties and genomics of glucose transporters. Curr Genomics (2007) 8:113-28. doi:10.2174/138920207780368187

84. Imasawa T, Obre E, Bellance N, Lavie J, Imasawa T, Rigothier C, et al. High glucose repatterns human podocyte energy metabolism during differentiation and diabetic nephropathy. FASEB J (2017) 31:294-307. doi:10.1096/ f. 201600293R

85. Sharma K, Karl B, Mathew AV, Gangoiti JA, Wassel CL, Saito R, et al. Metabolomics reveals signature of mitochondrial dysfunction in diabetic kidney disease. JAm Soc Nephrol (2013) 24:1901-12. doi:10.1681/ asn.2013020126

86. Wang Q, Somwar R, Bilan PJ, Liu Z, Jin J, Woodgett JR, et al. Protein kinase B/Akt participates in GLUT4 translocation by insulin in L6 myoblasts. Mol Cell Biol (1999) 19:4008-18. doi:10.1128/MCB.19.6.4008

87. van Dam EM, Govers R, James DE. Akt activation is required at a late stage of insulin-induced GLUT4 translocation to the plasma membrane. Mol Endocrinol (2005) 19:1067-77. doi:10.1210/me.2004-0413

88. Tolvanen TA, Dash SN, Polianskyte-Prause Z, Dumont V, Lehtonen S. Lack of CD2AP disrupts Glut4 trafficking and attenuates glucose uptake in podocytes. J Cell Sci (2015) 128:4588-600. doi:10.1242/jcs.175075

89. Bilodeau PS, Winistorfer SC, Allaman MM, Surendhran K, Kearney WR, Robertson AD, et al. The GAT domains of clathrin-associated GGA proteins have two ubiquitin binding motifs. J Biol Chem (2004) 279:54808-16. doi:10.1074/jbc.M406654200

90. Li LV, Kandror KV. Golgi-localized, gamma-ear-containing, Arf-binding protein adaptors mediate insulin-responsive trafficking of glucose transporter
4 in 3T3-L1 adipocytes. Mol Endocrinol (2005) 19:2145-53. doi:10.1210/ me.2005-0032

91. Poussu AM, Virtanen I, Autio-Harmainen H, Lehto VP. Podocyte-specific expression of a novel trans-Golgi protein Vear in human kidney. Kidney Int (2001) 60:626-34. doi:10.1046/j.1523-1755.2001.060002626.x

92. Shi J, Kandror KV. Sortilin is essential and sufficient for the formation of Glut4 storage vesicles in 3T3-L1 adipocytes. Dev Cell (2005) 9:99-108. doi:10.1016/j.devcel.2005.04.004

93. Ariga M, Nedachi T, Katagiri H, Kanzaki M. Functional role of sortilin in myogenesis and development of insulin-responsive glucose transport system in C2C12 myocytes. J Biol Chem (2008) 283:10208-20. doi:10.1074/jbc. M710604200

94. Lehtonen S, Zhao F, Lehtonen E. CD2-associated protein directly interacts with the actin cytoskeleton. Am J Physiol Renal Physiol (2002) 283:F734-43. doi:10.1152/ajprenal.00312.2001

95. Wasik AA, Koskelainen S, Hyvonen ME, Musante L, Lehtonen E, Koskenniemi K, et al. Ezrin is down-regulated in diabetic kidney glomeruli and regulates actin reorganization and glucose uptake via GLUT1 in cultured podocytes. Am J Pathol (2014) 184:1727-39. doi:10.1016/j.ajpath.2014.03.002

96. Coward RJ, Welsh GI, Koziell A, Hussain S, Lennon R, Ni L, et al. Nephrin is critical for the action of insulin on human glomerular podocytes. Diabetes (2007) 56:1127-35. doi:10.2337/db06-0693

97. Wasik AA, Polianskyte-Prause Z, Dong MQ, Shaw AS, Yates JR III, Farquhar MG, et al. Septin 7 forms a complex with CD2AP and nephrin and regulates glucose transporter trafficking. Mol Biol Cell (2012) 23:3370-9. doi:10.1091/ mbc.E11-12-1010

98. Beites CL, Campbell KA, Trimble WS. The septin Sept5/CDCrel-1 competes with alpha-SNAP for binding to the SNARE complex. Biochem J (2005) 385:347-53. doi:10.1042/bj20041090

99. Saito T, Yamada E, Okada S, Shimoda Y, Tagaya Y, Hashimoto K, et al. Nucleobindin-2 is a positive regulator for insulin-stimulated glucose transporter 4 translocation in fenofibrate treated E11 podocytes. Endocr J (2014) 61:933-9. doi:10.1507/endocrj.EJ14-0330

100. Yamada E, Okada S, Saito T, Ohshima K, Sato M, Tsuchiya T, et al. Akt2 phosphorylates Synip to regulate docking and fusion of GLUT4-containing vesicles. J Cell Biol (2005) 168:921-8. doi:10.1083/jcb.200408182

101. Yamada E, Saito T, Okada S, Takahashi H, Ohshima K, Hashimoto K, et al. Synip phosphorylation is required for insulin-stimulated Glut 4 translocation and glucose uptake in podocyte. Endocr J (2014) 61:523-7. doi:10.1507/ endocrj.EJ14-0099

102. Steimle PA, Fulcher FK, Patel YM. A novel role for myosin II in insulinstimulated glucose uptake in 3T3-L1 adipocytes. Biochem Biophys Res Commun (2005) 331:1560-5. doi:10.1016/j.bbrc.2005.04.082

103. Fulcher FK, Smith BT, Russ M, Patel YM. Dual role for myosin II in GLUT4-mediated glucose uptake in 3T3-L1 adipocytes. Exp Cell Res (2008) 314:3264-74. doi:10.1016/j.yexcr.2008.08.007

104. Wasik AA, Dumont V, Tienari J, Nyman TA, Fogarty CL, Forsblom C, et al. Septin 7 reduces nonmuscle myosin IIA activity in the SNAP23 complex and hinders GLUT4 storage vesicle docking and fusion. Exp Cell Res (2017) 350:336-48. doi:10.1016/j.yexcr.2016.12.010

105. Miyazaki Y, Cersosimo E, Triplitt C, DeFronzo RA. Rosiglitazone decreases albuminuria in type 2 diabetic patients. Kidney Int (2007) 72:1367-73. doi:10.1038/sj.ki.5002516

106. Ohtomo S, Izuhara Y, Takizawa S, Yamada N, Kakuta T, van Ypersele de Strihou C, et al. Thiazolidinediones provide better renoprotection than insulin in an obese, hypertensive type II diabetic rat model. Kidney Int (2007) 72:1512-9. doi:10.1038/sj.ki.5002570

107. Schernthaner G, Matthews DR, Charbonnel B, Hanefeld M, Brunetti P; Quartet [Corrected] Study Group. Efficacy and safety of pioglitazone versus metformin in patients with type 2 diabetes mellitus: a double-blind, randomized trial. J Clin Endocrinol Metab (2004) 89:6068-76. doi:10.1210/ jc.2003-030861

108. Filippone EJ, Gupta A, Farber JL. Normoglycemic diabetic nephropathy: the role of insulin resistance. Case Rep Nephrol Urol (2014) 4:137-43. doi:10.1159/000364901

109. Musso C, Javor E, Cochran E, Balow JE, Gorden P. Spectrum of renal diseases associated with extreme forms of insulin resistance. Clin J Am Soc Nephrol (2006) 1:616-22. doi:10.2215/cjn.01271005 
110. Diez-Sampedro A, Lenz O, Fornoni A. Podocytopathy in diabetes: a metabolic and endocrine disorder. Am J Kidney Dis (2011) 58:637-46. doi:10.1053/j. ajkd.2011.03.035

111. Lewko B, Bryl E, Witkowski JM, Latawiec E, Angielski S, Stepinski J. Mechanical stress and glucose concentration modulate glucose transport in cultured rat podocytes. Nephrol Dial Transplant (2005) 20:306-11. doi:10.1093/ndt/gfh612

112. Lennon R, Pons D, Sabin MA, Wei C, Shield JP, Coward RJ, et al. Saturated fatty acids induce insulin resistance in human podocytes: implications for diabetic nephropathy. Nephrol Dial Transplant (2009) 24:3288-96. doi:10.1093/ndt/gfp302

113. Kiritoshi S, Nishikawa T, Sonoda K, Kukidome D, Senokuchi T, Matsuo T, et al. Reactive oxygen species from mitochondria induce cyclooxygenase- 2 gene expression in human mesangial cells: potential role in diabetic nephropathy. Diabetes (2003) 52:2570-7. doi:10.2337/diabetes.52.10.2570

114. Thallas-Bonke V, Thorpe SR, Coughlan MT, Fukami K, Yap FY, Sourris KC, et al. Inhibition of NADPH oxidase prevents advanced glycation end product-mediated damage in diabetic nephropathy through a protein kinase C-alpha-dependent pathway. Diabetes (2008) 57:460-9. doi:10.2337/ db07-1119

115. Mezzano S, Aros C, Droguett A, Burgos ME, Ardiles L, Flores C, et al. NF-kappaB activation and overexpression of regulated genes in human diabetic nephropathy. Nephrol Dial Transplant (2004) 19:2505-12. doi:10.1093/ ndt/gfh207

116. Hasegawa G, Nakano K, Sawada M, Uno K, Shibayama Y, Ienaga K, et al. Possible role of tumor necrosis factor and interleukin-1 in the development of diabetic nephropathy. Kidney Int (1991) 40:1007-12. doi:10.1038/ki.1991.308

117. Berthier CC, Zhang H, Schin M, Henger A, Nelson RG, Yee B, et al. Enhanced expression of Janus kinase-signal transducer and activator of transcription pathway members in human diabetic nephropathy. Diabetes (2009) 58:469-77. doi:10.2337/db08-1328

118. Du P, Fan B, Han H, Zhen J, Shang J, Wang X, et al. NOD2 promotes renal injury by exacerbating inflammation and podocyte insulin resistance in diabetic nephropathy. Kidney Int (2013) 84:265-76. doi:10.1038/ki.2013.113
119. Ikezumi Y, Suzuki T, Karasawa T, Kawachi H, Nikolic-Paterson DJ, Uchiyama M. Activated macrophages down-regulate podocyte nephrin and podocin expression via stress-activated protein kinases. Biochem Biophys Res Commun (2008) 376:706-11. doi:10.1016/j.bbrc.2008.09.049

120. Isshiki K, Haneda M, Koya D, Maeda S, Sugimoto T, Kikkawa R. Thiazolidinedione compounds ameliorate glomerular dysfunction independent of their insulin-sensitizing action in diabetic rats. Diabetes (2000) 49:1022-32. doi:10.2337/diabetes.49.6.1022

121. Sarafidis PA, Stafylas PC, Georgianos PI, Saratzis AN, Lasaridis AN. Effect of thiazolidinediones on albuminuria and proteinuria in diabetes: a meta-analysis. Am J Kidney Dis (2010) 55:835-47. doi:10.1053/j.ajkd.2009. 11.013

122. Ma LJ, Marcantoni C, Linton MF, Fazio S, Fogo AB. Peroxisome proliferatoractivated receptor-gamma agonist troglitazone protects against nondiabetic glomerulosclerosis in rats. Kidney Int (2001) 59:1899-910. doi:10.1046/j.1523-1755.2001.0590051899.x

123. Yamahara K, Kume S, Koya D, Tanaka Y, Morita Y, Chin-Kanasaki M, et al. Obesity-mediated autophagy insufficiency exacerbates proteinuria-induced tubulointerstitial lesions. J Am Soc Nephrol (2013) 24:1769-81. doi:10.1681/asn. 2012111080

124. Tagawa A, Yasuda M, Kume S, Yamahara K, Nakazawa J, Chin-Kanasaki M, et al. Impaired podocyte autophagy exacerbates proteinuria in diabetic nephropathy. Diabetes (2016) 65:755-67. doi:10.2337/db15-0473

Conflict of Interest Statement: The authors declare that the research was conducted in the absence of any commercial or financial relationships that could be construed as a potential conflict of interest.

Copyright (c) 2018 Wasik and Lehtonen. This is an open-access article distributed under the terms of the Creative Commons Attribution License (CC BY). The use, distribution or reproduction in other forums is permitted, provided the original author(s) and the copyright owner are credited and that the original publication in this journal is cited, in accordance with accepted academic practice. No use, distribution or reproduction is permitted which does not comply with these terms. 